\title{
Contribuições da semântica da enunciação para a análise de texto
}

\author{
Contributions of enunciation semantics to text analysis
}

\author{
Carolina de Paula Machado ${ }^{1}$ \\ Universidade Federal de São Carlos
}

\begin{abstract}
- RESUMO: A Semântica Enunciativa desenvolvida por Eduardo Guimarães com base na noção enunciação como acontecimento de linguagem traz uma nova abordagem para a análise de texto. Suas reflexões, desde os trabalhos que publica em conjunto com Eni Orlandi até o enfoque mais argumentativo e enunciativo, trazem contribuições inestimáveis não só para a área de Semântica como também para a análise de texto. Neste artigo, pretendemos realizar um percurso por suas reflexões que explicam como o texto se faz uma unidade de sentido num primeiro momento, primeiro pensando a relação com o sujeito autor e as condições de produção do texto, depois, de forma mais analítica, por meio da orientação argumentativa realizada pelas conjunções e a relação com o sujeito na enunciação e, por fim, como os conceitos semânticos permitem que se realize uma interpretação de texto. Seu trajeto pela análise semântica e enunciativa do sentido realiza a ponte entre a semântica e a análise de texto.
\end{abstract}

- PALAVRAS-CHAVE: Texto. Sentido. Orientação argumentativa. Sujeito. Relação integrativa.

- ABSTRACT: The Enunciative Semantics developed by Eduardo Guimarães is based on the notion of enunciation as a language event and it brings a new approach to the text analysis. Guimarães' reflections, since the works that he publishes in pair with Eni Orlandi, until the more argumentative and enunciative approach, they bring invaluable contributions not only to the Semantics area as well as to text analysis. In this article, we intend to walk through his reflections that explain how the text becomes a unit of meaning (at first), thinking first about the relation with the author-subject and the production conditions of the text. Next, in a more analytical way, throughout the argumentative orientation executed by the conjunctions and the relation with the subject in the enunciation. Finally, we intend to see how the semantic concepts allow a text interpretation to be performed. His path through semantic and enunciative analysis of meaning creates a bridge between semantics and text analysis.

- KEYWORDS: Text. Meaning. Argumentative orientation. Subject. Integrative relation.

Uma das principais formas de funcionamento da língua na sociedade acontece através do texto. O texto é uma materialidade fundamental através da qual o homem se significa, é significado e atribui sentidos para o real. Embora seja tão comum em nosso dia a dia, produzido muitas vezes automaticamente, perguntas como "o que é texto?", "o que faz um texto ser um texto?" não são tão facilmente respondidas ${ }^{2}$.

Nos estudos linguísticos, encontramos o texto definido como "unidade de significado" ou "unidade de sentido". Meu propósito, neste artigo, é explicar como

\footnotetext{
${ }^{1}$ Doutora em Linguística pela UNICAMP. Professora do Departamento de Letras da UFSCar.

2 Este artigo é um dos resultados dos meus estudos realizados no interior do meu projeto de pósdoutorado intitulado "Texto, textualidade e sentido: aspectos semânticos na unidade textual", realizado na Unicamp, sob a supervisão da profa. Dra. Ana Cláudia Fernandes Ferreira, entre agosto de 2019 e julho de 2020.
} 
semanticista Eduardo Guimarães define texto e, mais do que isso, como ele desvenda o que faz dele uma unidade de significado e propõe uma forma de interpretação de texto com base na Semântica ${ }^{3}$.

Para isso, vou destacar e discutir alguns conceitos trabalhados por ele no interior da semântica da enunciação que o permitiram construir uma descrição dos sentidos no texto. Trata-se de conceitos como os de função-autor, orientação argumentativa, progressão textual, estratégias de relação, designação, reescrituração e relação integrativa.

Em seu trabalho, o linguista inova ao abordar o texto do interior da semântica, uma vez que a palavra e o enunciado/sentença/frase são as unidades de análise tradicionais dessa área da Linguística no interior do estruturalismo, do formalismo e do gerativismo. Mas chegou um momento em que a Linguística busca ir além desses limites e por diferentes caminhos, seja pelo discurso, pela enunciação, pela pragmática ou pela linguística de texto.

Guimarães, por seu turno, desenvolve uma semântica enunciativa e mobiliza conceitos semânticos e enunciativos que dão subsídios teóricos e metodológicos para que se possa não só descrever a organização textual como, também, para que se possa realizar a interpretação do texto, distinguindo-se de abordagens que têm como propósito descrever a coesão e a coerência, o gênero, etc., pois para ele, "a questão do texto é uma questão semântica" (2011, p. 09).

Inicialmente, do lugar de semanticista, ele se sustenta teoricamente na Análise do Discurso, na Enunciação, e na Argumentação Linguística, que dão um suporte teórico para tratar o sentido constituído no texto pela historicidade, pelo social, pelo político e pelo ideológico. De um lado, ele distingue-se de uma abordagem referencial para descrever o sentido; por outro, seu trabalho emerge na década de 1980, época em que as Teorias do Texto ganham força com noções como as de coesão e coerência, e com abordagens cognitivas e pragmáticas do sujeito e da situação, e propõe uma abordagem de aspectos semânticos e enunciativos do texto, mas com o sujeito constituído histórico e socialmente na e pela linguagem, sendo que os sentidos emergem da materialidade textual pela relação com a sua enunciação o que aproxima a semântica ao campo das ciências humanas ${ }^{4}$.

\section{Saindo da evidência da completude do texto}

Num primeiro momento, Guimarães e Orlandi $(1985)^{5}$ buscam responder a questões importantes quando se toma o texto como objeto de estudo: "Por que um conjunto de palavras, de frases, etc. é um texto reconhecível enquanto tal? Como dar um sentido, ou sentidos, a este conjunto, como algo que tem uma unidade?"

\footnotetext{
3 E. Guimarães trabalha na perspectiva da semântica enunciativa e pela abordagem discursiva que realizou, iniciou a Semântica Histórica da Enunciação. Posteriormente, após ter elaborado um quadro teórico específico, a teoria passou a ser nomeada de Semântica do Acontecimento, nome de um de seus livros.

${ }^{4}$ Guimarães faz uma interessante discussão sobre os estudos semânticos no Brasil no seu livro "História da Semântica". A questão do sujeito passa a fazer parte dos estudos sobre a linguagem a partir dos anos 70 do século XX, o que aproxima os estudos linguísticos às ciências humanas em contraposição a outros estudos linguísticos que ficam mais próximos das ciências exatas e/ ou das ciências biológicas.

${ }^{5}$ Texto publicado por E. Guimarães feito em co-autoria com E. Orlandi, de 1985, produzido no interior do Projeto Ipê do governo do Estado de São Paulo voltado para a "atualização e aperfeiçoamento de professores e especialistas".
} 
Essas questões desestabilizam algumas ideias que podem ser consideradas como parte de um discurso fundador dos primeiros estudos que se dedicaram ao texto. Uma delas seria a ideia de que um texto é uma soma de frases ${ }^{6}$, de que seria suficiente saber formar uma frase gramaticalmente aceita para que se pudesse produzir um texto juntando várias frases.

Outro ponto fundamental é quando eles dizem que "sem dúvida, nesta questão está envolvido o modo como as palavras, frases, sequências se organizam enquanto texto"(1985, p.3) . Percebemos a contraposição a outro discurso comum: o de que a articulação textual dava-se do mesmo modo que a articulação gramatical da frase. Esta ideia também circulou nas primeiras reflexões sobre o texto, a chamada fase "transfrástica" da Linguística Textual. E o que se mostrou posteriormente pela própria linguística textual com os conceitos de coesão e coerência, dentre outros, é que o texto possui uma organização própria que difere da sintaxe do nível frasal.

É assim que Orlandi e Guimarães partem de duas questões centrais sobre o texto ao mesmo tempo em que se distanciam do percurso que a linguística textual trilhou, por encararem o objeto texto não em sua evidência como um produto acabado, fechado em si mesmo, completo, herança da concepção de língua como sistema de signos, mas dedicam-se a explicar os processos de produção dos sentidos e sua organização que está relacionada com as condições em que o texto é produzido.

Eles problematizam a evidência de unidade e de completude do texto. Em outro artigo intitulado "Unidade e dispersão: uma questão do texto e do sujeito", também de 1985, os autores discorrem justamente sobre o efeito ideológico de que o texto se dá como uma unidade mas, para eles, uma unidade fundada na "dispersão de sujeitos" ou seja, o sujeito ocupa várias posições sendo que estas podem representar diferentes formações discursivas e citam Foucault (1969) definindo texto "como espaço de dissensões múltiplas”(p. 53). Neste momento, o que eles consideram como posição sujeito são as figuras enunciativas de Locutor, locutor enquanto pessoa no mundo e enunciador.

Como então tratar o texto pela evidência de unidade e, ao mesmo tempo, como processo que expõe sua heterogeneidade?

Entra então o sentido. A frase é relacionada ao texto por meio do sentido: “(...) constatamos que uma frase significa algo em virtude do texto de que faz parte. Ao mesmo tempo, este sentido é contribuição da frase em questão para o sentido do texto." (p. 4). Vemos que é o sentido/significado o responsável pelo texto ser algo que tem unidade deslocando assim a articulação sintática para segundo plano, ou seja, é o sentido produzido nesta articulação que dá a unidade, e não a articulação em si. Nesta citação vemos o início da reflexão que desembocará na relação integrativa futuramente.

Ainda, segundo os autores, o conjunto de frases torna-se um texto porque o texto é produzido por um falante para um ouvinte, em uma determinada situação, para alguma finalidade.

Os autores afirmam que "um texto pode ser constituído por uma palavra, uma frase ou uma sequência de um grande número de frases. $\mathrm{O}$ que define o texto não é a sua extensão mas o fato de que ele é uma unidade de sentido em relação à situação.”(1985, p. 4).

\footnotetext{
${ }^{6}$ Indursky (2006) explica-nos que entre as décadas de 50-60 havia linguistas que tomavam a frase como objeto da linguística e havia outro grupo de linguistas que não se convenciam disso. O que era comum a elas era a dúvida sobre se um texto seria "uma simples soma de frases"(p. 43).

${ }^{7} \mathrm{O}$ artigo foi apresentado originalmente em seminário na PUC-SP no ano de 1985 e publicado em Cadernos PUC, n $^{\circ}$ 31, 1988 e no livro Discurso e Leitura de 1988.
} 
Os autores não deslocam apenas o olhar do produto acabado para o processo. Mais do que isso, podemos considerar que o que eles fazem é deslocar o foco da superfície textual, isto é, da descrição do modo como se constrói a referência no texto por meio das relações anafóricas e catafóricas, para descrever o sentido constituído pela historicidade e pela prática social. O sentido torna-se o articulador desta unidade que se chama texto na qual podemos ter outras unidades de sentido, sejam enunciados, seja apenas uma palavra. Os limites de uma palavra, de uma frase, eram o que antes se considerava como o que determinava os limites de um texto. Agora são os sentidos dessas unidades que são dispostos em função do sentido do texto.

Um segundo ponto crucial que é discutido é o modo como a organização do texto culmina na unidade dada pelo engajamento do autor. O sujeito ${ }^{8}$ é posto em cena na produção do(s) sentido(s) do texto e o conceito de função de autor, para produzir a unidade, é fundamental. A ilusão de unidade dar-se-ia pelo do princípio de autoria. $\mathrm{O}$ autor seria então uma função social e histórica do $e u$.

Segundo eles, o autor é o responsável por construir a consistência do texto. Trata-se de um "projeto totalizante de um sujeito-falante" para dar coerência e completude ao texto. "(...) o sujeito-falante marca suas posições de inúmeras maneiras, mas, pela função de autor, amarra essas diferentes posições num todo. E isto se dá em certas condições." (1985, p. 05). A relação gramatical no texto não é determinante para a produção de sua unidade como vemos.

Como um dos procedimentos de organização do texto, os autores trazem as conjunções e expressões que ocorrem com a mesma função. "Podemos dizer que um conjunto de frases ou sequências é um texto, do ponto de vista da sua organização, porque o sentido destas frases ou sequências indica para uma mesma direção de interpretação" (p. 7).(...) Como a dispersão de sujeitos e discursos torna-se esta unidade de sentido que é o texto? Vemos aí já o início de uma reflexão que será desenvolvida depois por Guimarães, de como essa organização se dá através do funcionamento das conjunções.

\section{As conjunções e a disparidade do sujeito no texto}

É então no livro Texto e Argumentação: um estudo das conjunções do Português, de 1987, que Guimarães detalha o modo como a dispersão se torna unidade por meio do das conjunções.

Não se trata de pensar as conjunções no campo das relações sintáticas como meros conectores, mas como operadores argumentativos. E isso é feito relacionando-se enunciado com a sua enunciação e como isso afeta a direção argumentativa no texto.

$\mathrm{O}$ funcionamento argumentativo marca a "representação do sujeito na constituição do sentido" na enunciação. Guimarães sustenta-se em uma concepção de enunciação que não se centra no sujeito que se apropria da língua. Traz então a definição de Ducrot (1984) (apud Guimarães, 2007, p12) em que a enunciação é “o evento histórico do aparecimento do enunciado".

Esta é uma diferença importante em relação a outras abordagens do texto: não se trata de lidar com o autor empírico, o que levaria a tratar das intenções, fechando a

\footnotetext{
${ }^{8} \mathrm{Na}$ Análise de discurso materialista, bem como para a semântica do acontecimento, não utilizamos a categoria de homem ou de ator, mas a de sujeito que é aquele constituído na e pela linguagem. Trata-se das posições de sujeito (para a $\mathrm{AD}$ ) ou da representação do sujeito na enunciação (para a Semântica do Acontecimento-SA). De acordo com Orlandi (2001), "a ideologia interpela o indivíduo em sujeito e este submete-se à língua significando e significando-se pelo simbólico na história.”(p.100)
} 
interpretação, completando o texto com uma interpretação como "aquilo que o autor quis dizer". Descentralizar o sujeito do dizer a partir desta definição de enunciação permite que ele trabalhe com a ideia de sujeito da enunciação como representações na enunciação, permite tratar dos efeitos de sentidos possíveis de serem produzidos, ou seja, da incompletude do texto, sob a ilusão de unidade.

É assim que ele descreve o texto do seguinte modo:

unidade empírica com começo, meio e fim, que tomaremos como unidade de análise. Mas consideraremos que esta unidade empírica deve ser pensada no processo discursivo. E nesta perspectiva podemos dizer que o texto é atravessado por várias posições do sujeito, sendo, também, uma dispersão de discursos.

E continua:

Constitui ainda o texto a representação de uma posição específica do sujeito (a de autor) que procura criar a ilusão da unidade textual. Ao mesmo tempo em que procura criar a unidade do sujeito. Torna-se, então, importante, ver como a dispersão constitui a textualidade pela representação desta unidade. (GUIMARÃES, 1987,p. 13)

Esta definição traz a visão de que o texto é uma "dispersão de discursos" em função das várias posições do sujeito. Unidade e dispersão não se opõem, elas convivem. A questão é como o texto se faz unidade sendo uma dispersão.

A aproximação com teorização da Análise de discurso continua, como vemos, e possibilita lidar com a contradição do funcionamento do texto: "ver como a dispersão constitui a textualidade pela representação desta unidade.”(1987,p.13)

\subsection{Cisão do Sujeito, orientação argumentativa e a unidade do texto}

O sentido, para Guimarães (1987), são efeitos da enunciação que se representam no enunciado, na forma da orientação argumentativa e da representação do sujeito da enunciação. Isto significa que o sentido do texto produzido por um sujeito autor resulta de um cruzamento de sentidos de outras posições do sujeito ${ }^{9}$ das quais uma predomina devido à orientação argumentativa produzida pelas conjunções, em função do projeto de unidade do sujeito autor.

As conjunções são mecanismos linguísticos internos ao texto que produzem a orientação argumentativa, fundamental para que se construa a unidade de sentido. Então, mesmo que diversos sentidos, de posições distintas perpassem o texto, há a direção argumentativa para um certo sentido que predomina em relação aos demais, que pode ou não ser assumido pelo locutor-autor.

\footnotetext{
${ }^{9}$ No enunciado, o sujeito é representado por meio de diferentes papeis, isto é, representa-se o que ele chama de "cisão fundamental do sujeito". O enunciado é polifônico, contém uma dialogia interna que constitui o sentido. Influência do conceito de polifonia de Bakhtine discutido no interior da Semântica Linguística por O. Ducrot. Guimarães leva em conta a coexistência de vozes presente no enunciado, seguindo a linha ducrotiana, mas incorpora à teoria da enunciação, do pensamento de Bakhtine, o aspecto histórico-social para analisar o locutor (locutor enquanto pessoa no mundo, o lp).
} 


\subsubsection{As conjunções mas e embora e seu papel semântico-enunciativo na textualidade}

Em função da importância das conjunções na unidade textual, destacaremos agora aspectos do funcionamento semântico-enunciativo-argumentativo das conjunções ${ }^{10}$ mas e embora descritos pelo autor que as analisa comparativamente.

Consideramos esta análise como emblemática do papel da conjunção na organização textual, pois a análise evidencia o papel delas na progressão textual e nas estratégias de relação.

\section{i) A Progressão Textual}

Um aspecto de grande importância para o texto é a sua progressão, ou seja, o seu desenvolvimento em prol de uma conclusão. As conjunções mas e embora são conhecidas por articularem argumentos que se contrapõem. Vejamos com mais acuidade o papel delas na tessitura do texto.

A função do mas $^{11}$ argumentativo, chamado de mas PA, é a de "introduzir uma proposição $\boldsymbol{q}$ que orienta para uma conclusão não-r oposta a uma conclusão $\boldsymbol{r}$ para a qual p poderia conduzir: ele é inteligente, mas PA estuda pouco." (Vogt, 1980, p.104).

A abordagem feita pela semântica argumentativa nos mostra que a função do mas não é opor proposições mas opor as conclusões a que os argumentos articulados por ela levam, revelando portanto a relação dos enunciados com a enunciação, ou seja, com o sentido que se deve interpretar a partir do que é dito.

Assim, o sentido do enunciado, segundo Vogt (1980, p. 110), "não é constituído por condições de verdade, mas pelas continuações de que o enunciado é suscetível num encadeamento argumentativo".

Guimarães, por sua vez, investiga que efeitos a orientação argumentativa $^{12}$ produzida pela conjunção mas teria se fosse analisada para além dos limites do enunciado, em um texto. A comparação entre o embora e o mas feita por ele nos apresenta uma característica importante, o papel da conjunção mas na organização textual.

Em uma sequência representada por $\mathbf{X}$, mas $\mathbf{Y}$, em que $\mathbf{X}$ e $\mathbf{Y}$ são dois enunciados articulados pelo mas, "a continuação do texto se articula com a oração que tem o mas"(p.110). Já no caso do embora a continuidade do texto se articula com a oração que não tem o embora.

\footnotetext{
${ }^{10}$ Outras conjunções e locuções são analisadas por ele: logo, pois, já que, e, além disso, não só ... mas também, ou ...ou, para que, quando, que.

${ }^{11} \mathrm{O}$ mas analisado é a mas argumentativo chamado de mas PA que se distingue do mas SN, não argumentativo. C. Vogt (1980) afirma que o mas que tem a função de conjunção adversativa deriva do advérbio latino magis e não do adversativo latino sed. Segundo ele, as línguas românicas que utilizam o mas derivado do magis, atribuem a ele duas funções: uma retificadora, que corresponde ao sino do espanhol e ao sondern do alemão; e a outra função é, realizada pelo pero do espanhol e pelo aber do alemão, que é a função de opor conclusões. Ao mas que realiza a primeira função, ele chama de mas $\mathrm{SN}$ enquanto o mas que realiza a segunda função ele nomeia como mas PA.

12 Guimarães utiliza a seguinte definição de orientação argumentativa: "Orientar argumentativamente com um enunciado X é apresentar seu conteúdo A como devendo conduzir o interlocutor a concluir C (também um conteúdo). Ou seja, orientar argumentativamente é dar A como uma razão para se crer em C (Anscombre e Ducrot, 1976, p. 13 apud Guimarães, 1987, p. 25)." Este conceito é importante porque distingue a posição da semântica argumentativa de posições filiadas à retórica pois não se trata de convencimento.
} 
Com a conjunção mas, o texto progride levando em conta a direção indicada pelo argumento introduzido por ele. Vamos reproduzir aqui um dos recortes analisados por Guimarães com o mas:

(A) (X) "/Os incidentes de Leme envergonham o País/,/mas

(B) (Y) o País não parece estar envergonhado/./

(C) (Z) A nação não está tomada por um sentimento doloroso de estupor ou de indignação." (Senhor, 279,22/07/86, p. 22) - (T 7) A

Correndo o risco de sermos reducionistas, vamos tentar resumir as conclusões da análise feita por Guimarães. Segundo ele, após fazer a descrição do sentido do recorte por meio da representação em escala argumentativa ${ }^{13}$, o que se diz em (C) é uma continuidade do que se diz em (B), mais especificamente, (C) é dito segundo a direção argumentativa de (B). (A) pode ter como conclusão "O País se revolta", enquanto (B) teria como conclusão "O país não se revolta". E o enunciado $(\mathbf{C})$ segue a direção argumentativa para a conclusão que se pode tirar de (B). Segundo Guimarães, o jornalista constrói o texto na direção do sentido da "acomodação do País, diante desses fatos" e essa direção é definitiva para o texto como um todo.

Quando se utiliza o embora, no entanto, o texto progride na direção argumentativa posta pelo argumento não introduzido pelo embora. Vejamos outro recorte analisado por ele ${ }^{14}$.

“... Já pelos temas, fica bem marcado o caráter interdisciplinar da reunião.

(Y) / Embora o tema central enfatizasse a necessidade de uma discussão ampla dos problemas do Oeste brasileiro com um todo/,/

(X) o Pantanal acabou por se tornar a grande estrela do evento//

(Z) o que, afinal, já era de se esperar, visto que o encontro atraiu para Campo Grande as maiores autoridades brasileiras no assunto"/ (Ciência Hoje, Vol. 4: 24, p. 80, 1986) T8

Para o autor, as conclusões devem ser tiradas mediante a situação. É assim que a conclusão $\mathbf{r}$ seria "O congresso não se ateve ao tema central proposto" e $\sim \mathbf{r}$ seria "O congresso se ateve ao tema central proposto.

$\mathrm{O}$ texto dá-se na direção argumentativa posta pelo argumento (X), que orienta para a conclusão "O congresso não se ateve ao tema central proposto" como vemos com o enunciado $(Z)$.

O título do texto é "III Reunião Regional da SBPC. Por um novo oeste" e ele relata que as discussões se dão apenas em torno do Pantanal, por isso vemos que as "conclusões $\mathbf{r}$ e $\sim \mathbf{r}$ têm então, a força de estabelecer as direções gerais para onde os sentidos do texto indicam e como esse pode tomá-lo com um todo." (p. 115).

Assim, vemos como as conclusões as quais as conjunções levam, afetam a continuidade do texto como um todo.

É interessante ver que para ele, não se trata de pensar no conteúdo do argumento mas de olhar para as posições que esses argumentos revelam:

vê-se deste modo como a direção argumentativa para a qual os operadores argumentativos indicam não são segmentos futuros do texto, mas são lugares

\footnotetext{
${ }^{13}$ Em suas análises, o autor utiliza os conceitos de classe e escala argumentativas. Constitui-se uma classe argumentativa, "enunciados cujos conteúdos, regularmente, se apresentam como argumentando para uma conclusão"(Guimarães, 2007, p. 27). Por outro lado, a "escala argumentativa é uma classe argumentativa em que se configura uma relação de força maior ou menor dos conteúdos dos enunciados."(idem, p. 28)

${ }^{14}$ Para ver a descrição do sentido de forma mais detalhada, recomendamos a leitura do livro "Texto e argumentação: um estudo das conjunções do português".
} 
semânticos que organizam o texto para além, ou aquém de sua segmentalidade. (GUIMARÃES, 2007, p. 115).

Podemos ver pela retomada das análises feitas por Guimarães a importância que as conjunções mas e embora têm para a progressão do texto para uma certa direção. Cada uma a seu modo determina a continuidade do texto, pela maneira como articula os argumentos enunciados de certas perspectivas e lugares sociais, e, consequentemente, para a conclusão a que ele pode levar dependendo da situação. "Mais uma vez fica clara a importância da consideração da conclusão para a qual tais recortes indicam. Ou seja, a organização textual tem como um de seus fundamentos a orientação argumentativa." (1987, p. 116)

Com isso vemos que a unidade textual é construída desde a articulação feita pelas conjunções e que não se trata de uma questão sintática. A abordagem semânticoenunciativa revela que se trata de uma questão de sentido e das representações do sujeito na enunciação. As outras conjunções analisadas por ele, de modos diversos, também contribuem para a unidade do texto.

\section{ii) Representação do sujeito e as Estratégias de Relação}

Como vimos, a unidade de sentido do texto faz-se pela predominância de uma direção argumentativa para uma certa conclusão definida pelo modo como cada conjunção organiza os argumentos como vimos anteriormente. Isso não significa, entretanto, que todos os argumentos envolvidos no texto orientem para a mesma conclusão, pois eles podem levar a conclusões de posições distintas. As conjunções cujas análises retomamos acima operam os argumentos de modo a ir se construindo no texto a predominância de uma certa conclusão.

Com isso, Guimarães passa à segunda característica importante do funcionamento semântico-enunciativo-argumentativo das conjunções: as diferentes conclusões a que levam os argumentos pela articulação com os operadores argumentativos se dão de diferentes perspectivas enunciativas.

O Locutor apresenta várias perspectivas que são chamadas de enunciadores (E1, E2, etc). O Locutor assume uma dessas perspectivas: há uma perspectiva que prevalece, isto é, aquela em torno da qual o texto se organiza, tem sua continuidade. Ela pode ser a perspectiva assumida pelo Locutor ou não, mas a partir da predominante, busca-se dar unidade ao texto, revelando o jogo das direções argumentativas e, ao mesmo tempo, a construção da unidade textual. A organização textual dá-se em função da orientação argumentativa e das representações do sujeito da enunciação. A perspectiva predominante dá a direção da progressão textual. Além da perspectiva, esse locutor também enuncia como locutor enquanto pessoa no mundo, isto é, ele é caracterizado socialmente.

Trazer à tona a representação do sujeito na enunciação, descrever a mobilização de várias perspectivas na enunciação é fundamental para a análise de enunciados e textos. Muitas vezes, nos textos, temos que falar de perspectivas que não assumimos, com as quais não concordamos, dependendo do tipo de texto que estamos produzindo. A percepção dessa divisão do sujeito na enunciação é, portanto, fundamental para a interpretação.

No posfácio desse livro publicado posteriormente, Guimarães faz uma importante reflexão sobre o fato de que a argumentatividade não se restringe à relação do sujeito com os argumentos, um desdobramento importante uma vez que não se trata da escolha ou vontade do sujeito sobre o que é dito nem de uma questão de 
convencimento do alocutário sobre as conclusões resultantes da direção argumentativa. O que sustenta a passagem do argumento para a conclusão é a temporalidade do acontecimento enunciativo. Para o autor,

(...) no acontecimento enunciativo, a construção da temporalidade, ao construir um passado, ao recortar um memorável, constitui o sentido que funciona como elemento que autoriza a passar de um argumento a uma conclusão, que dá consistência, no sentido colocado logo acima, à orientação argumentativa. (GUIMARÃES, 2007, pp. 210-211).

É portanto um já dito, atualizado no presente do acontecimento de enunciação, que garante orientação argumentativa construída no texto.

Vejamos agora o que o autor chama de estratégias de relação:

Retomemos o enunciado analisado:

"Sequência 284 - Os incidentes de Leme envergonham o País, mas o país não parece estar envergonhado. A nação não está tomada por um sentimento doloroso de estupor ou de indignação. (Senhor, 279, 22/07/86, p. 22) T 7."

Conforme a análise do operador argumentativo mas, a continuidade do texto acontece na direção argumentativa de mas o país não se revolta. Neste caso, temos um Locutor que enuncia de uma perspectiva enunciativa $\mathrm{E} 0{ }^{15}$ quando diz que os incidentes do Leme envergonham o país e de uma perspectiva E1 quando diz que o país não parece estar envergonhado. A progressão textual acontece na direção dada pela perspectiva E1 que não é a assumida pelo Locutor.

Então usar $X$ mas $Y$ é equivalente a usar $X$ embora $Y$ ? Considerando os sentidos produzidos na enunciação, essas duas conjunções produzem sentidos bem diferentes e organizam o texto de maneiras diferentes direcionando-o para conclusões diferentes.

Vejamos as substituições que ele faz:

(294) Os incidentes de Leme envergonham o País, mas o País não parece estar envergonhado.

(295) O País não parece estar envergonhado, embora os incidentes de Leme o envergonhem.

(296) Embora os incidentes de Leme envergonhem o País, ele não parece estar envergonhado.

Todos estes enunciados orientam para "O país não se revolta".

No primeiro enunciado, o $\mathbf{2 9 4}$, temos como tema Os incidentes de Leme envergonham o país. A estratégia consiste no Locutor iniciar com este tema mas, conforme Guimarães nos explica, ele frustra seu alocutário continuando com um comentário de uma outra perspectiva que não é a sua: mas o país não parece estar envergonhado.

\footnotetext{
${ }^{15}$ Lembrando que o autor embora fale em posição do sujeito, ele utiliza as categorias da enunciação Locutor (L), locutor enquanto pessoa no mundo (lp) e Enunciador (E) para descrever a cisão do sujeito na enuniciação.
} 
No caso do enunciado 295, o tema que é dado no início se mantém e coloca-se o comentário com o embora, com a perspectiva que não é a predominante, e a estratégia é a de manter o que se deu como início no enunciado, sendo o comentário apenas um contraponto.

No último caso, enunciado 296, o que é dado no início para o alocutário é o que não vai predominar na continuidade do enunciado algo que é refutado para então prevalecer o argumento predominante.

As estratégias de relação, que procuramos aqui caracterizar (...), são, então, uma representação no texto que cruza as posições do sujeito da enunciação (L, Lp, E) e o modo de relacionar com estas posições a representação das posições do alocutário e do destinatário (tema/comentário, orientação argumentativa).(GUIMARÃRES, 2007, P. 122)

Guimarães nos mostra com a análise do mas comparado ao embora como num texto o Locutor é agenciado na enunciação e enuncia de perspectivas enunciativas diversas e a articulação com uma ou outra conjunção e o posicionamento como tema ou comentário constituem-se como estratégias de produção de lugares que os leitores devem ocupar para interpretar a continuidade textual, mesmo que a posição em que o texto seguirá não seja a perspectiva assumida pelo lp.

Este livro representa muito mais do que seu conteúdo. Realizar um estudo das conjunções torna o texto um dos objetos da Semântica e da Enunciação. Suas análises transbordam os limites dos enunciados e mostram como as conjunções, tratadas por um viés morfológico como simples palavras gramaticais, são importantes elementos na constituição do(s) sentido(s) do texto. Não de um sentido estrito ao próprio texto, mas pela relação que estas palavras realizam entre língua e enunciação ao significarem diferentes posições do sujeito que vão sendo harmonizadas na organização textual de forma que uma perspectiva predomine e produza a ilusão de unidade do sujeito e do texto.

\section{A designação}

Se, por um lado, a análise dos operadores argumentativos, como uma das formas de articulação, permitiu a Guimarães mostrar o modo como o texto se faz unidade pela relação com a representação do sujeito na enunciação e a direção argumentativa, por outro, a designação, definida como a significação de um nome pelas relações linguísticas que simboliza o real (Guimarães, 2002), faz com que ele volte sua atenção para uma análise semântica que tem como unidade de análise o enunciado. Assim, seus trabalhos trazem análises de palavras no interior de enunciados considerando os textos. Para fazer as análises semânticas sem desconsiderar o texto, ele se utiliza da relação integrativa que descreveremos mais adiante.

A reescrituração (Guimarães, 2002, 2007) é o procedimento pelo qual a designação de uma palavra se dá. É interessante ver que ao se realizar a análise semântica acaba-se contribuindo para a compreensão dos textos, como veremos. Tratase de analisar como uma palavra é redita por outras palavras e como isso produz outros sentidos no acontecimento enunciativo, pela relação do presente da enunciação com o passado, isto é, com o memorável que é recortado. Segundo Guimarães, tanto a reescrituração quanto a articulação são procedimentos de textualidade.

Como vemos, a questão é, novamente, o sentido. O procedimento semântico de reescrituração possibilita identificar o que uma palavra designa no acontecimento enunciativo de um ou mais textos. Assim, muitos de seus trabalhos tomam como objeto 
descrever os sentidos de uma palavra. Ainda que esse método de análise parta de uma palavra, e que se tenha como objetivo uma análise semântica da palavra, isso tem como consequência que se descreva a tessitura textual por meio do sentido que vai se construindo para a/as palavras do texto analisado.

Embora o conceito de designação e o procedimento de reescrituração, que se observa para a análise da designação, advenham do desenvolvimento da teoria da Semântica do Acontecimento e não tenham como foco a análise de texto, são conceitos semânticos que podem ser usados para a análise de um texto pois a reescrituração é um dos mecanismos que produz a unidade de sentido do texto, juntamente com a articulação, por meio, dentre outras coisas, dos operadores argumentativos.

\section{A interpretação do texto}

Em um livro publicado por Guimarães em 2011, intitulado "Análise de texto: Procedimentos, Análises, Ensino" seu foco não é dizer o que faz com que um conjunto de frases seja um texto, mas de como se pode produzir uma análise textual, uma interpretação do texto do ponto de vista semântico.

Ele ressalta que do ponto de vista da linguística textual, há linguistas que consideram que o texto é uma unidade de sentido. Para ele, então, a questão da unidade do texto é uma questão semântica, colocando então o problema do texto como unidade como algo de caráter semântico.

Não se trata de dizer que a semântica irá se ocupar da análise de texto, segundo ele, mas de usar conceitos semânticos que propiciem a realização da interpretação textual sem desconsiderar as particularidades da organização textual que diferem o texto do enunciado. De como o sentido de expressões linguísticas, de enunciados, contribuem para o sentido do texto e vice-versa.

A mudança no modo de abordar a questão do texto que é feita por ele coloca conceitos semânticos e enunciativos em função da análise textual, fazendo com que a Semântica Enunciativa contribua para a análise e interpretação dos textos ao realizar uma descrição da produção do sentido.

\subsection{A Relação Integrativa}

Um passo fundamental em sua reflexão é recorrer à noção de integração discutida por E. Benveniste. Ela preenche uma lacuna quando se considera que a unidade de sentido do texto se faz por relações de sentido entre enunciados e texto. Isto porque estas relações não são cumulativas, não se reduzem à superfície do texto, nem são referenciais, mas acontecem por um funcionamento específico entre as palavras no texto no acontecimento enunciativo, que recortam um passado já dito, o atualizam no presente e projetam um futuro de interpretação.

\footnotetext{
A pertinência de um objeto finito ao qual se atribui o nome "texto" não diz respeito à sequência em si, mas à relação desta sequência com o acontecimento de enunciação em que ela se apresenta. Uma sequência de linguagem tem sua finitude configurada na relação com o lugar de enunciação do Locutor no acontecimento de linguagem." (GUIMARÃES, 2011, pp. 26-27)
}

Ele define o texto da seguinte forma: 
Texto é uma unidade de sentidos que integra enunciados no acontecimento de enunciação. Esta definição considera de modo direto que o texto é uma unidade de significação. Ela se caracteriza por produzir sentido e é isso que faz dela (desta unidade) um texto. Outro aspecto é que esta unidade (o texto) integra enunciados, ou dito de outro modo, o texto é integrado por enunciados. E é isto que faz com que o texto seja texto e faça sentido (GUIMARÃES, 2011, p. 19).

Nesta nova definição de texto, já com a teoria da Semântica de Acontecimento consolidada, o sentido continua sendo o aspecto fundamental do que Guimarães compreende como sendo o texto. Para Elias de Oliveira (2012) a diferença desta definição é que a unidade textual dá-se em função do acontecimento enunciativo enquanto que na primeira, a unidade dá-se em função do processo discursivo.

Outra questão é importante para a unidade que agora é explicada pela relação de integração trazida de Émile Benveniste de seu artigo "Os níveis de análise Linguística"(1966).

Como forma de ilustrar este aspecto da relação entre palavras, enunciados e texto no acontecimento de enunciação que explica o sentido do texto não ser resultado da soma do sentido dos enunciados, ele descreve a relação entre os nomes das ruas no mapa da cidade tratando o mapa como unidade de significação. O mapa traz os nomes das ruas e indicações de sua localização. Os nomes se organizam no mapa por relação de contiguidade (uns ao lado dos outros sem conectores) não havendo nenhum aspecto sintático que os articule. Os nomes significam por pertencerem a esta unidade superior que os reúne. A integração diz respeito à integração de um elemento linguístico a outro superior que lhe dá o sentido. Não é que um nome só signifique em um texto, mas ganha significados específicos ao ser integrado por ele.

A relação integrativa vem para explicar a passagem do nível do enunciado para o texto.

\subsection{Metodologia: uma questão de detalhe}

Baseado em dois autores da análise literária, Leo Spitzer e Rifaterre, é pelo detalhe que se busca chegar em uma interpretação do texto, da totalidade da obra. Zoppi Fontana (2012) destaca a análise minuciosa feita por Guimarães que, ao partir de uma da expressão "os que" chega aos sentidos de "cidadão" na constituição do Império. Assim, é através de uma palavra que integra o enunciado que integra o texto, no acontecimento enunciativo, que se pode iniciar a análise do texto, considerando, é claro, os objetivos específicos. O detalhe perpassa toda a produção dele.

E é aí então que para realizar a interpretação do texto, ele traz da Semântica do Acontecimento conceitos que são funcionamentos que produzem a textualidade de um texto: a reescrituração e a articulação. Além desses conceitos, ele mobiliza todo o quadro conceitual da teoria para realizas as análises de textos, como cena enunciativa, acontecimento enunciativo, etc. Antes, eles eram conceitos usados para analisar os sentidos de uma palavra. $\mathrm{Na}$ análise de textos, o que se faz agora e analisar o modo como os sentidos de uma palavra contribuem para o sentido do enunciado no texto.

Como ele afirma, a semântica não tem como objetivo estudar o texto, entretanto, o que o semanticista faz é buscar usar os conceitos desenvolvidos em semântica para interpretar, analisar os textos, um trabalho fundamental uma vez que, como ele próprio afirma, a questão do texto é semântica. 


\section{Considerações finais}

Nosso intuito foi o de realizar um percurso sobre o texto por alguns dos trabalhos do semanticista Eduardo Guimarães nos quais ele analisa e descreve seu objeto: o sentido. Como resultado de seu esforço teórico e metodológico realizado ao longo de anos de trabalho para fazer uma semântica com base na análise linguística, sem se restringir à estrutura e trazendo a exterioridade para o domínio da linguagem, ele conseguiu nos proporcionar, com o suporte inicial de conceitos discursivos e, depois, com conceitos elaborados a partir da teoria semântico-enunciativa, uma sólida teoria que hoje nos possibilita tanto realizar uma análise semântica de uma palavra, como de um enunciado como de um texto, se ser furtar ao lugar de semanticista.

Trazendo o problema da unidade/dispersão das reflexões feitas com Orlandi, no horizonte de retrospecção, ele consegue mostrar a convivência dessa contradição por meio da análise da orientação argumentativa e da representação dos vários papeis do sujeito na enunciação que conferem a unidade de sentido do texto.

Depois, os conceitos de designação e o procedimento de reescrituração assim como a releitura que ele faz da relação integrativa o levam a propor um procedimento de análise ou interpretação de texto pelo viés da semântica.

Enfim, seu trabalho realiza uma tão necessária ponte entre a Semântica e o estudo do texto por meio da constituição dos sentidos no texto, uma abordagem que traz suporte teórico para a interpretação dos textos e permite a leitores, sejam escolares ou não, uma via de trabalho com o texto que não se reduz a identificar características formais e inferir "o que o autor quis dizer" mas que foca definitivamente no sentido.

\section{REFERÊNCIAS}

BENVENISTE, É. Problemas de linguística geral I (1966). $5^{\mathrm{a}}$ ed. Campinas, SP: Pontes Editores, 2005.

ELIAS DE OLIVEIRA, S. Análise de texto: um olhar de semanticista. Resenha. Conexão Letras, $\quad$ V. $07, \quad \mathrm{n}^{\mathrm{o}} \quad 8 . \quad$ Disponível em: https://seer.ufrgs.br/conexaoletras/article/view/55452 Acesso em: 22/11/2019.

GUIMARÃES, E. Texto e Argumentação: um estudo de conjunções do português.(1987). Campinas, SP. Pontes, $4^{a}$ edição revista e ampliada. 2007.

- Semântica do acontecimento: um estudo enunciativo da designação. Campinas, SP: Pontes, 2002.

. História da Semântica: sujeito, sentido e gramática no Brasil. Campinas, SP: Pontes, 2004.

. Análise de texto: Procedimentos, Análises, Ensino. Campinas, SP: Editora $\overline{\mathrm{RG}, 2011 .}$.

INDURSKY, F. O texto nos estudos da linguagem: especificidades e limites. In: Orlandi, E.; Lagazzi-Rodrigues, S. (orgs). Discurso e textualidade. Campinas, SP: Pontes, 2006. p. 33-80.

KOCH,I.V. A Coesão Textual.(1989) 20ª ed. São Paulo: Editora Contexto, 2005.

VOGT, C. De magis a mas: uma hipótese semântica. In: Linguagem, pragmática e ideologia. São Paulo: Hucitec; Campinas, SP: Fundação de Desenvolvimento da Unicamp, 1980. p. 103-128.

ORLANDI, E.; GUIMARÃES, E. Projeto Ipê: atualização e aperfeiçoamento de professores e especialistas em educação por multimeios. Língua Portuguesa III. 
Governo Democrático do Estado de São Paulo, Secretaria de Estado da Educação -SP, Coordenadoria de estudo e normas pedagógicas, 1985.

ORLANDI, E. Unidade e Dispersão: uma questão do texto e dos sujeitos. In: Discurso e Leitura. $3^{\text {a }}$ ed. São Paulo: Cortez; Campinas, SP: Editora da Universidade de Campinas, 1996. p. 53-74.

\section{1.}

Discurso e Texto: Formulação e circulação dos sentidos. Campinas: Pontes,

ZOPPI FONTANA,M. A arte do detalhe. In: Revista Web discursividade. Edição ${ }^{\circ}{ }^{9}$, Jan-Maio/2012.

Disponível

em:

http://www.discursividade.cepad.net.br/EDICOES/09/Arquivos/zopi.pdf Acesso em: $17 / 11 / 2019$.

Recebido em: novembro de 2019.

Aprovado em: dezembro de 2019.

\section{Como citar este trabalho:}

MACHADO, C. de P. Contribuições da semântica da enunciação para a análise de texto. Traços de Linguagem. V.3, n.2, p. 28-41, 2019. 